Supplement of Atmos. Chem. Phys., 20, 5887-5897, 2020

https://doi.org/10.5194/acp-20-5887-2020-supplement

(C) Author(s) 2020. This work is distributed under

the Creative Commons Attribution 4.0 License.

(c) (1)

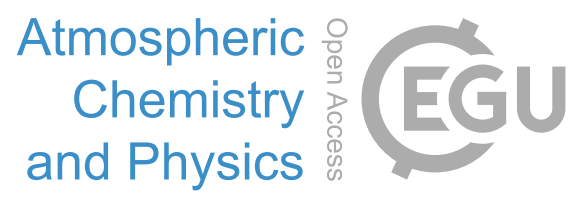

Supplement of

\title{
Contribution of hydroxymethanesulfonate (HMS) to severe winter haze in the North China Plain
}

\section{Tao Ma et al.}

Correspondence to: Fengkui Duan (duanfk@mail.tsinghua.edu.cn) and Kebin He (hekb@tsinghua.edu.cn)

The copyright of individual parts of the supplement might differ from the CC BY 4.0 License. 


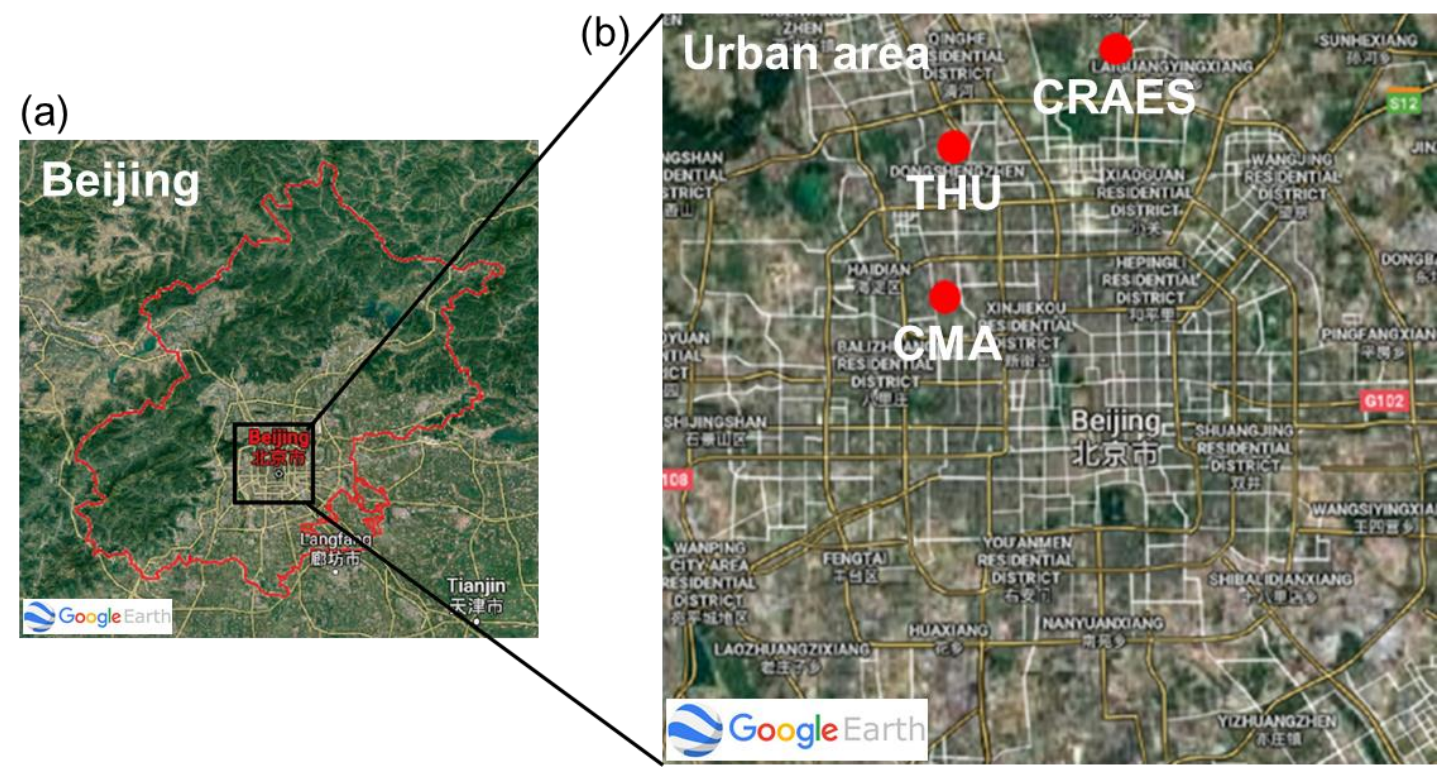

Figure S1. Location of observational sites in urban Beijing. (a) Map of Beijing. (b) Observational sites in the urban area of Beijing. The THU, CMA, and CRAES sites represent the Tsinghua University $\left(40.00^{\circ} \mathrm{N}, 116.34^{\circ} \mathrm{E}\right)$, the Chinese Academy of Meteorological Sciences $\left(39.95^{\circ} \mathrm{N}, 116.33^{\circ} \mathrm{E}\right)$, and the Chinese Research Academy of Environmental Sciences $\left(40.05^{\circ} \mathrm{N}, 116.42^{\circ} \mathrm{E}\right)$, respectively. (C) Google Earth 

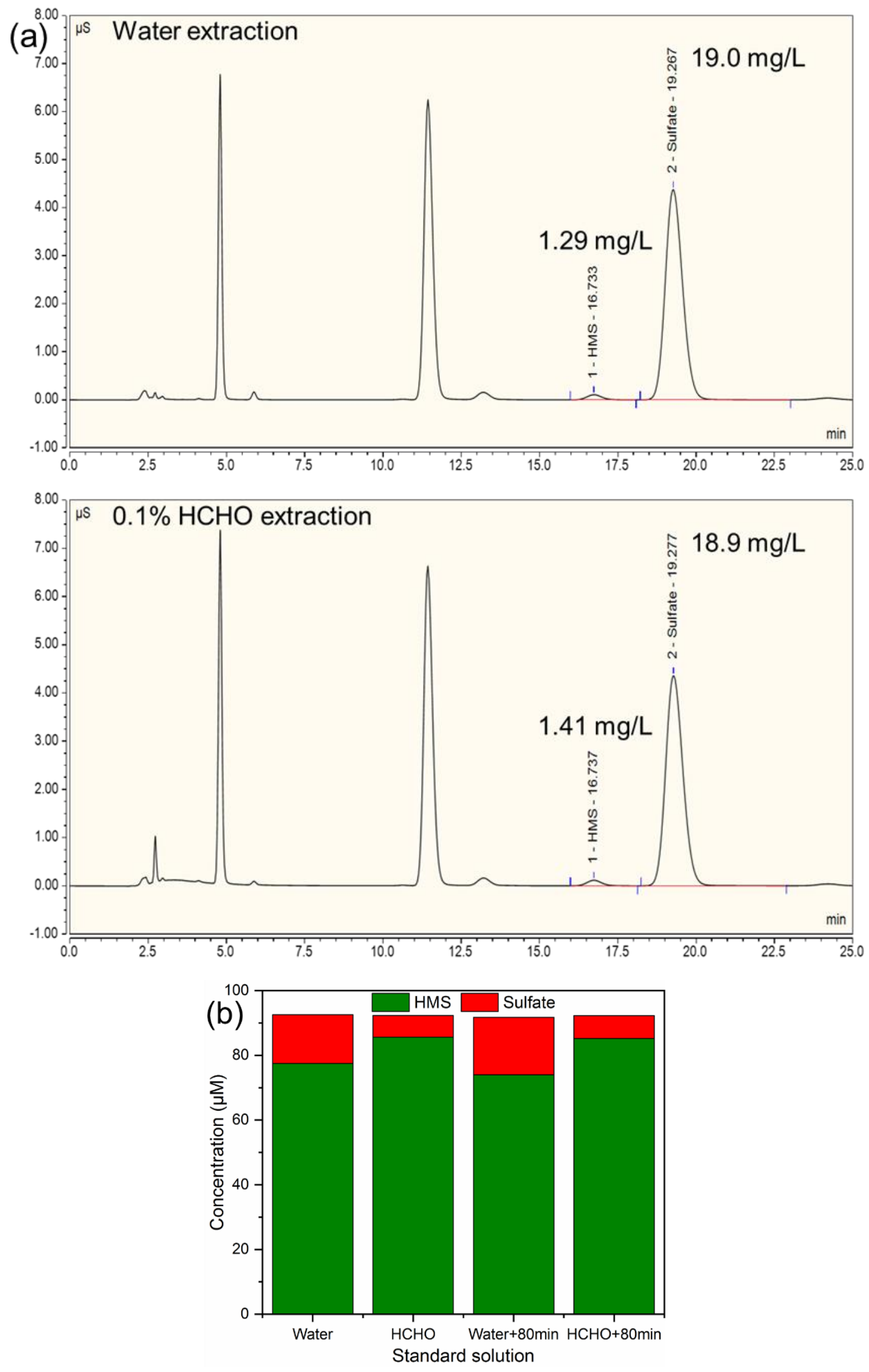

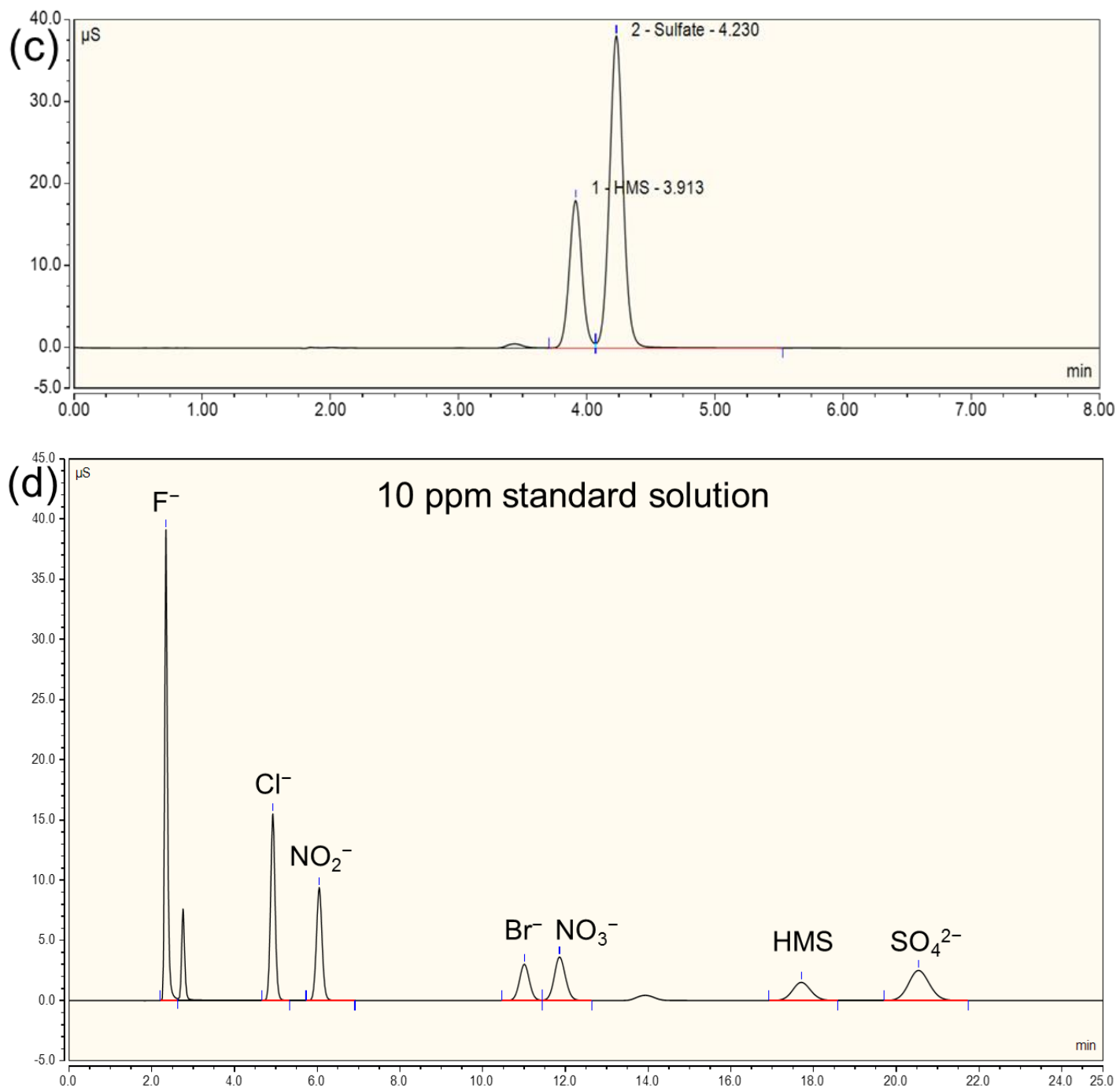

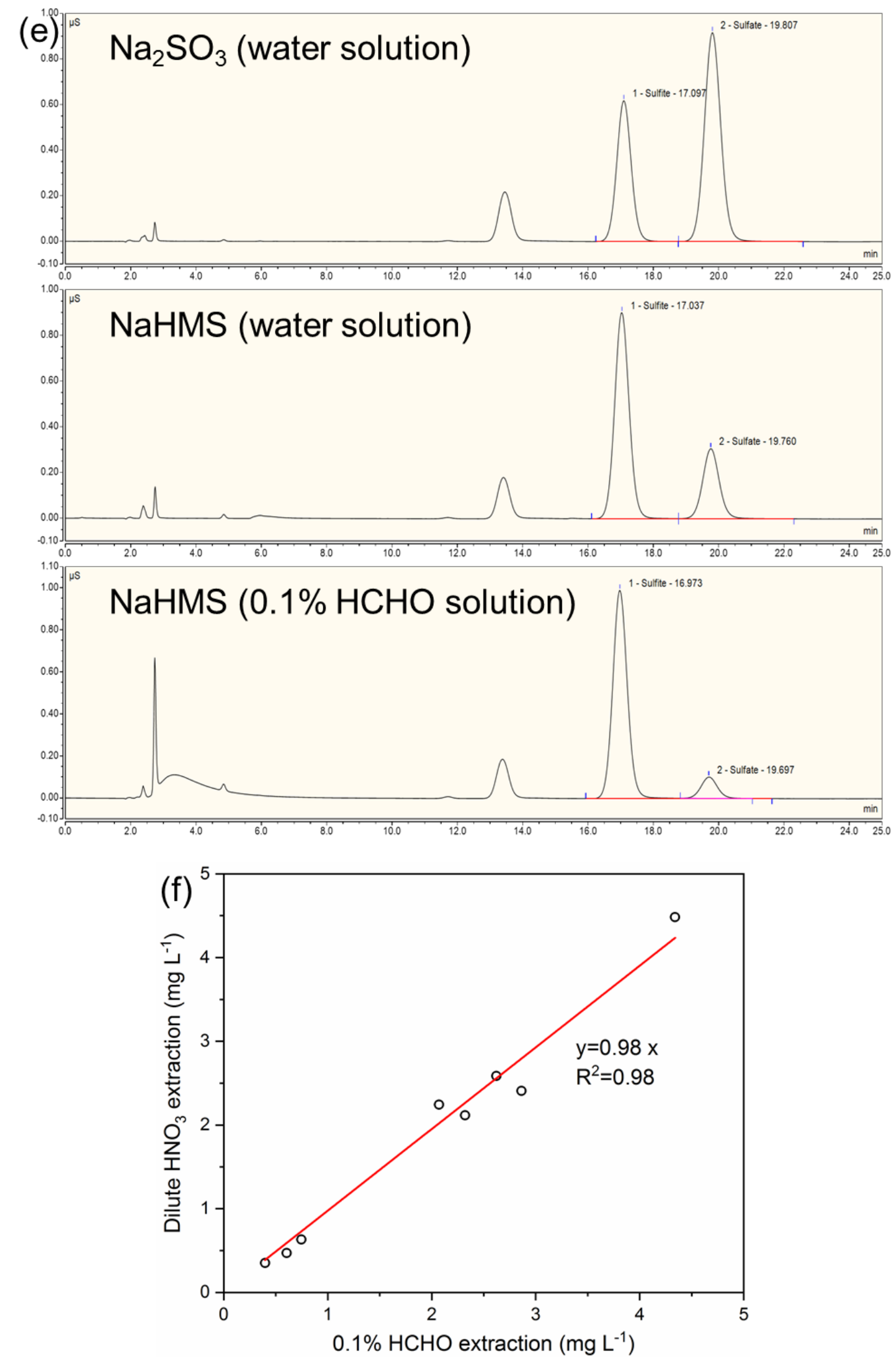

Figure S2. HMS quantification by ion chromatography. (a) Comparison of sample ion chromatography spectrum after water extraction and $0.1 \% \mathrm{HCHO}$ extraction. The ion chromatography is conducted immediately after sample extraction. (b) Evolution of 
HMS standard solution (purity: 97\%) over time in water extraction and $0.1 \% \mathrm{HCHO}$ extraction. (c) Separation of HMS and sulfate in AS11-HC column with $30 \mathrm{mM} \mathrm{KOH}$ eluent. (d) Ion chromatogram spectrum of a $10 \mathrm{ppm}$ mixed standard solution in the AS11-HC column with $11 \mathrm{mM} \mathrm{KOH}$ eluent. (e) Ion chromatography spectrum of standard $\mathrm{Na}_{2} \mathrm{SO}_{3}, \mathrm{NaHMS}$, and NaHMS $+0.1 \% \mathrm{HCHO}$ solution. The retention time of $\mathrm{Na}_{2} \mathrm{SO}_{3}$ (purity: $\geq 98 \%$ ), NaHMS (purity: $97 \%$ ), and $\mathrm{NaHMS}+0.1 \%$ HCHO samples are same. (f) Comparison between HMS concentration in dilute nitric acid $(\mathrm{pH} \approx 3)$ extraction and total $\mathrm{S}(\mathrm{IV})$ concentration in $0.1 \% \mathrm{HCHO}$ extraction in $\mathrm{PM}_{2.5}$ samples. The concentrations in both extractions are sulfite-equivalent concentration.

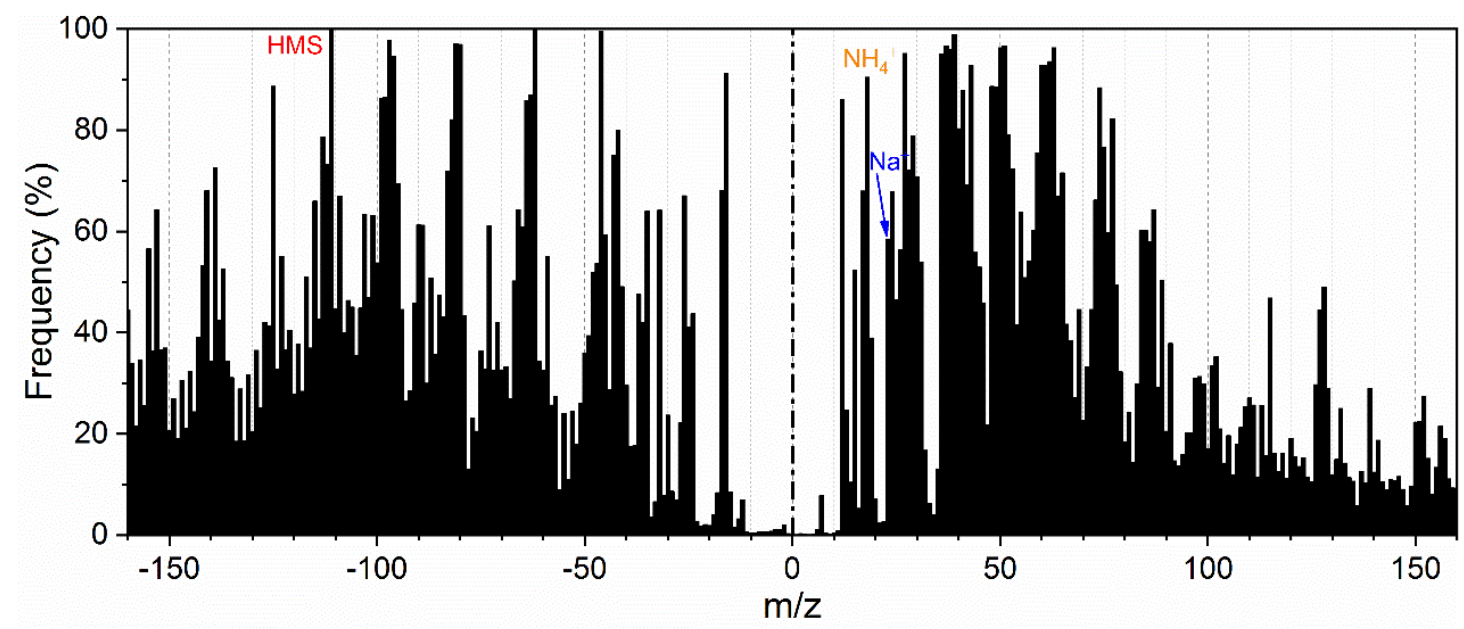

Figure S3. Positive and negative digital histograms of HMS-containing particles. The digital histogram represents the frequency of individual particles present at each $\mathrm{m} / \mathrm{z}$. 

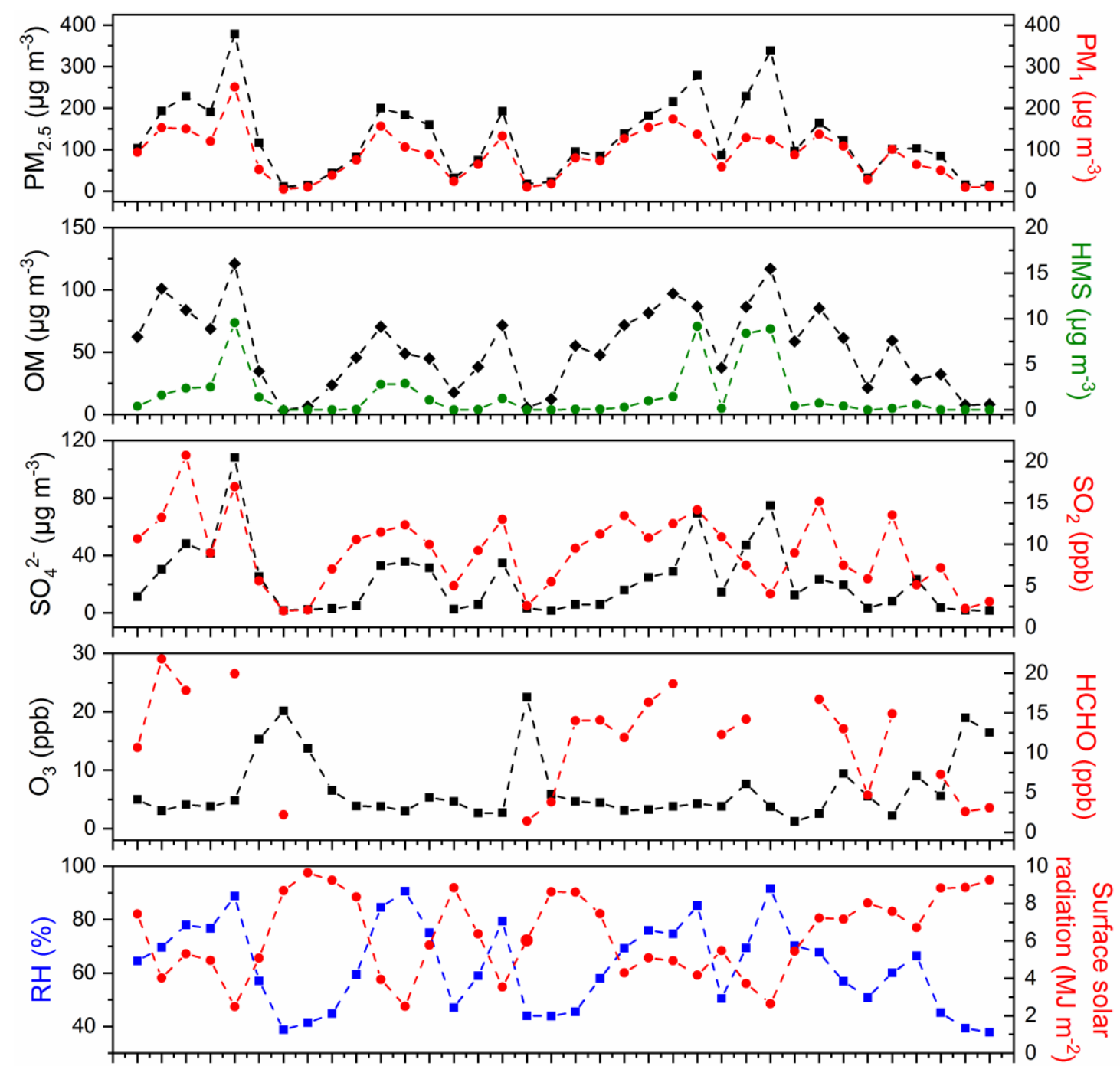

손

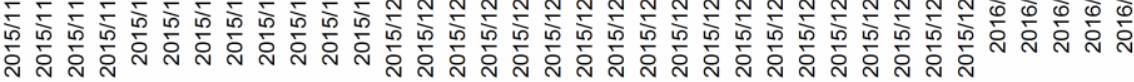

Sample

Figure S4. Characteristics of offline samples in winter 2015. Variation of $\mathrm{PM}_{2.5}, \mathrm{PM}_{1}$, organic matter (OM), $\mathrm{HMS}, \mathrm{SO}_{4}{ }^{2-}, \mathrm{SO}_{2}, \mathrm{O}_{3}, \mathrm{HCHO}$, relative humidity $(\mathrm{RH})$, and total surface solar radiation in winter 2015 . OM is estimated as 1.6 times of OC. $\mathrm{SO}_{4}{ }^{2-}$ and HMS concentrations are derived from offline $\mathrm{PM}_{2.5}$ samples measured by the optimized ion chromatography method, while other parameters are averages of online hourly data during sampling periods. 


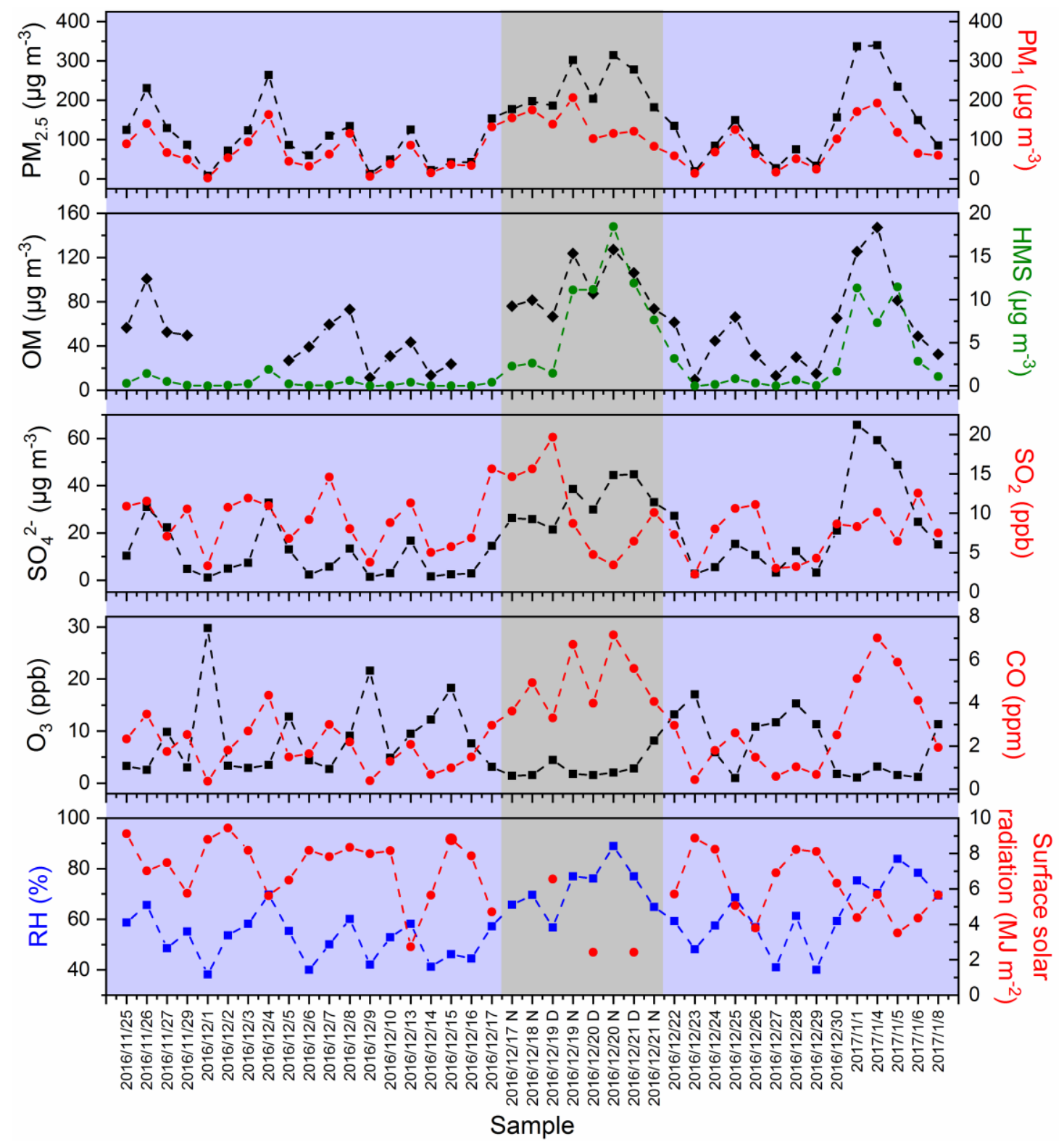

Figure S5. Characteristics of offline samples in winter 2016. Variation of $\mathrm{PM}_{2.5}, \mathrm{PM}_{1}$, organic matter $(\mathrm{OM}), \mathrm{HMS}, \mathrm{SO}_{4}{ }^{2-}, \mathrm{SO}_{2}, \mathrm{O}_{3}, \mathrm{CO}$, relative humidity $(\mathrm{RH})$, and total surface solar radiation in winter 2016. OM is estimated as 1.6 times of OC. The blue shade represents daily samples, and the gray shade represents half-day samples, where $\mathrm{D}$ and $\mathrm{N}$ correspond to samples collected during daytime and nighttime, respectively. $\mathrm{SO}_{4}{ }^{2-}$ and HMS concentrations are derived from offline $\mathrm{PM}_{2.5}$ samples measured by the optimized ion chromatography method, while other parameters are averages of online hourly data during sampling periods. 

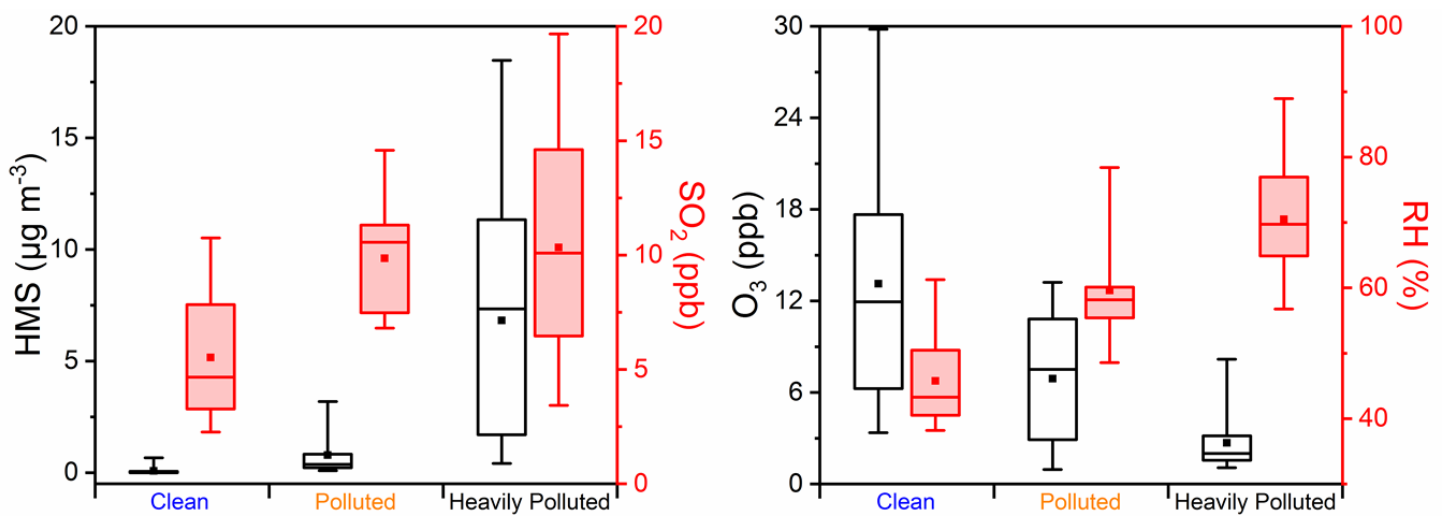

Figure S6. Evolution of HMS in Beijing winter of 2016. $\mathrm{HMS}, \mathrm{SO}_{2}, \mathrm{O}_{3}$, and relative humidity (RH) at different pollution levels from 24 November 2016 to 8 January 2017. 

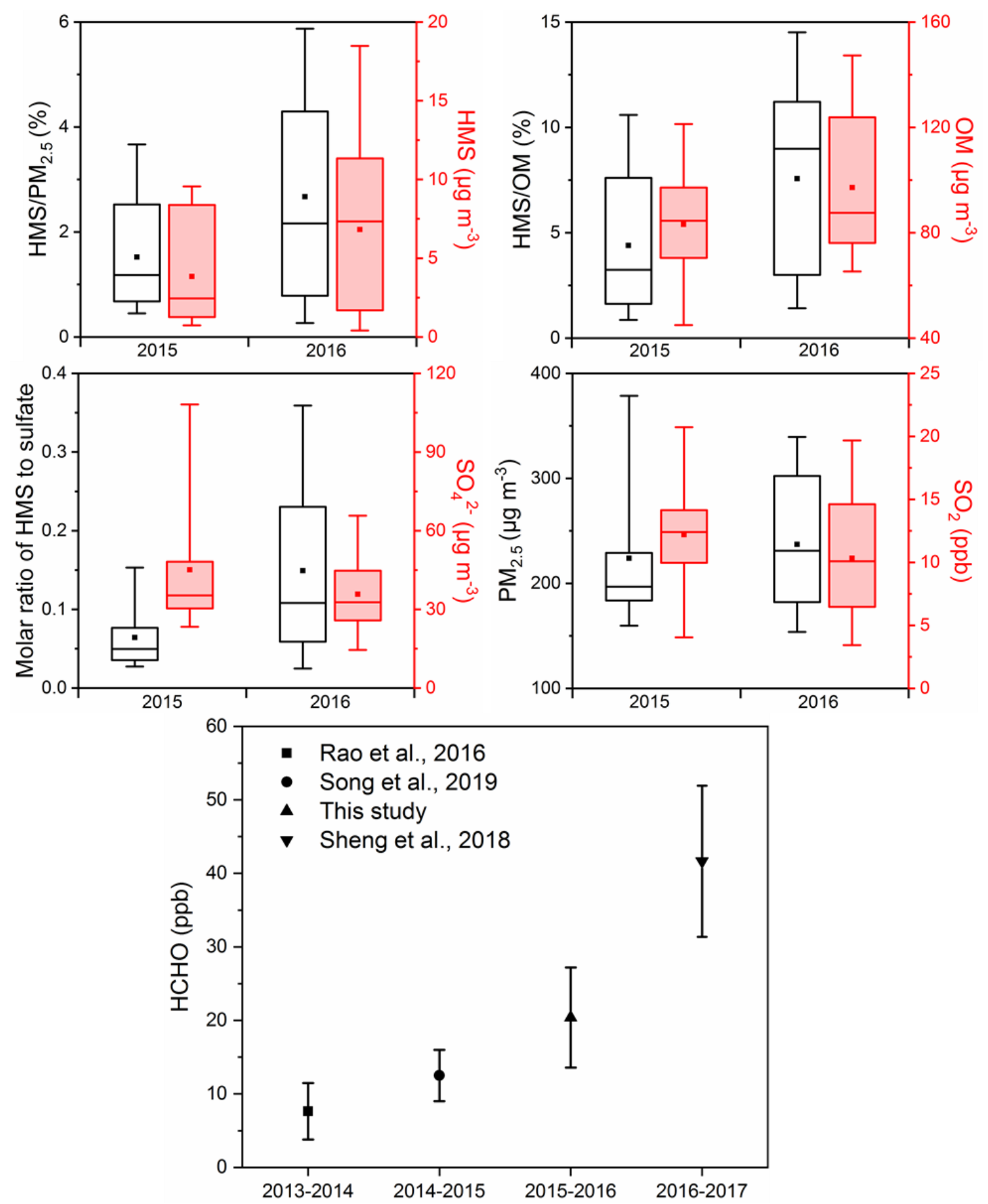

Figure S7. Change of haze characteristics in Beijing winter from 2015 to 2016. Variation of $\mathrm{HMS} / \mathrm{PM}_{2.5}, \mathrm{HMS}, \mathrm{HMS} / \mathrm{OM}, \mathrm{OM}$, the molar ratio of HMS to sulfate, $\mathrm{SO}_{4}{ }^{2-}, \mathrm{PM}_{2.5}$, and $\mathrm{SO}_{2}$ in Beijing winter from 2015 to $2016 . \mathrm{OM}$ is estimated as 1.6 times of OC. Variations in HCHO levels during winter haze in Beijing during 20132017. The HCHO concentrations in 2013-2014, 2014-2015, and 2016-2017 winter are derived from the work by Rao et al. (2016), Song et al. (2019), and Sheng et al. (2018), respectively. 

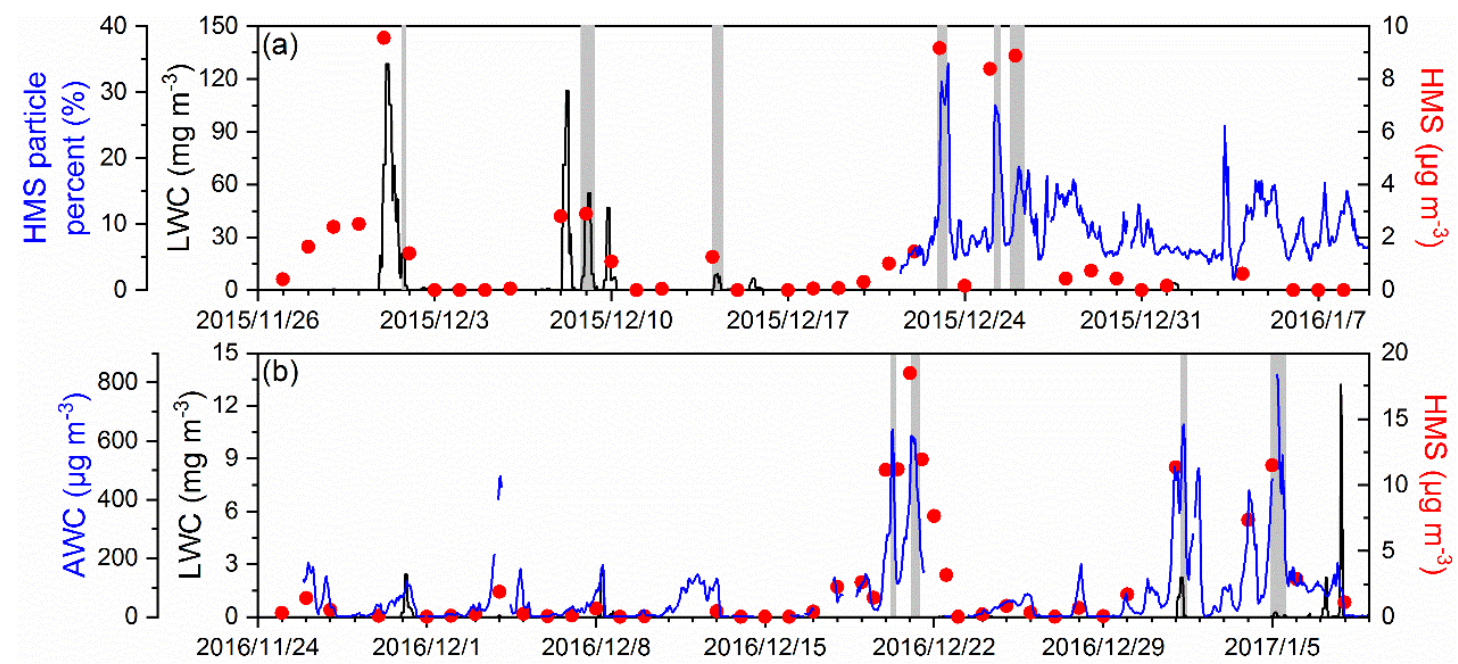

Figure S8. Relationship between HMS events and cloud/fog/aerosol water in Beijing winter. (a) Time series of HMS concentration, HMS-containing particle percentage, and cloud/fog liquid water content (LWC) in winter 2015. LWC is obtained from the MERRA-2 (Modern-Era Retrospective analysis for Research and Applications, Version 2) reanalysis meteorology (Gelaro et al., 2017). The average LWC below the planetary boundary layer height over the Beijing area is calculated and shown. The gray shades represent the possible presence of fog events $(\mathrm{RH}>90 \%)$. (b) Time series of HMS concentration, aerosol water content (AWC), and LWC in winter 2016.

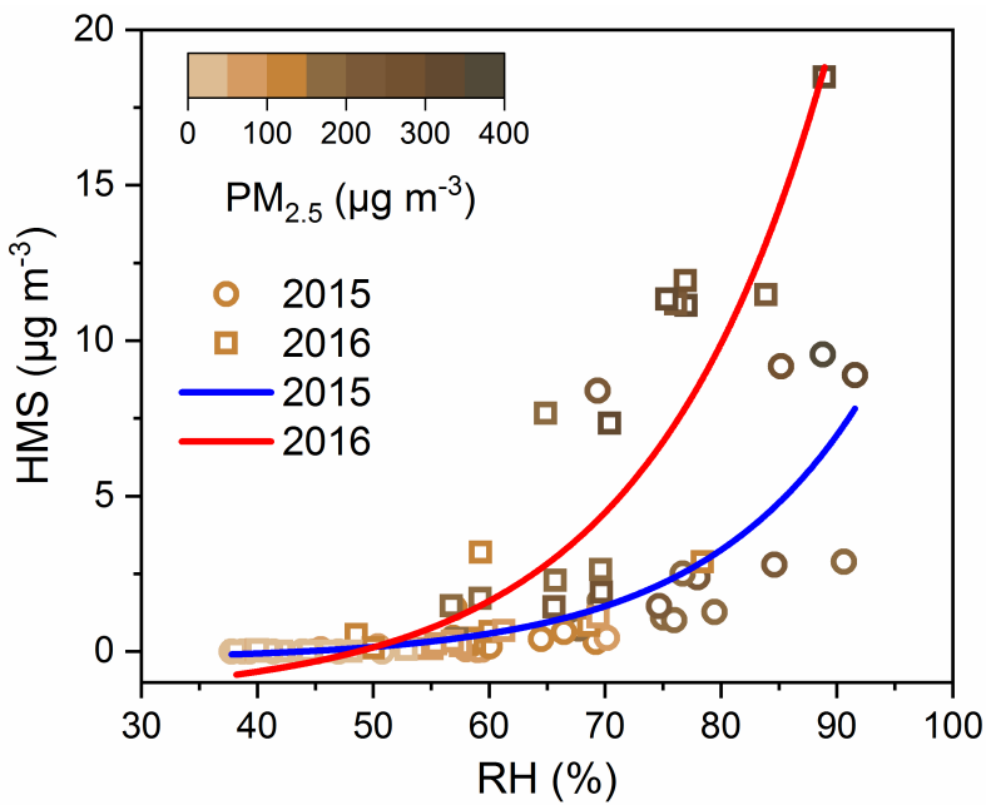

Figure S9. Effects of RH on HMS formation. Correlation between RH and HMS concentration in the winter of 2015 and 2016. The markers represent HMS concentrations and are colored by the $\mathrm{PM}_{2.5}$ concentrations. The blue and red curve represents the exponential fitting between RH and HMS concentration in 2015 and 2016 , i.e., $y=-0.27+1.2 \times 10^{-2} e^{0.072 x}\left(R^{2}=0.56\right)$ and $y=-1.51+6.5 \times 10^{-2} e^{0.065 x}\left(R^{2}=\right.$ $0.78)$, respectively. 


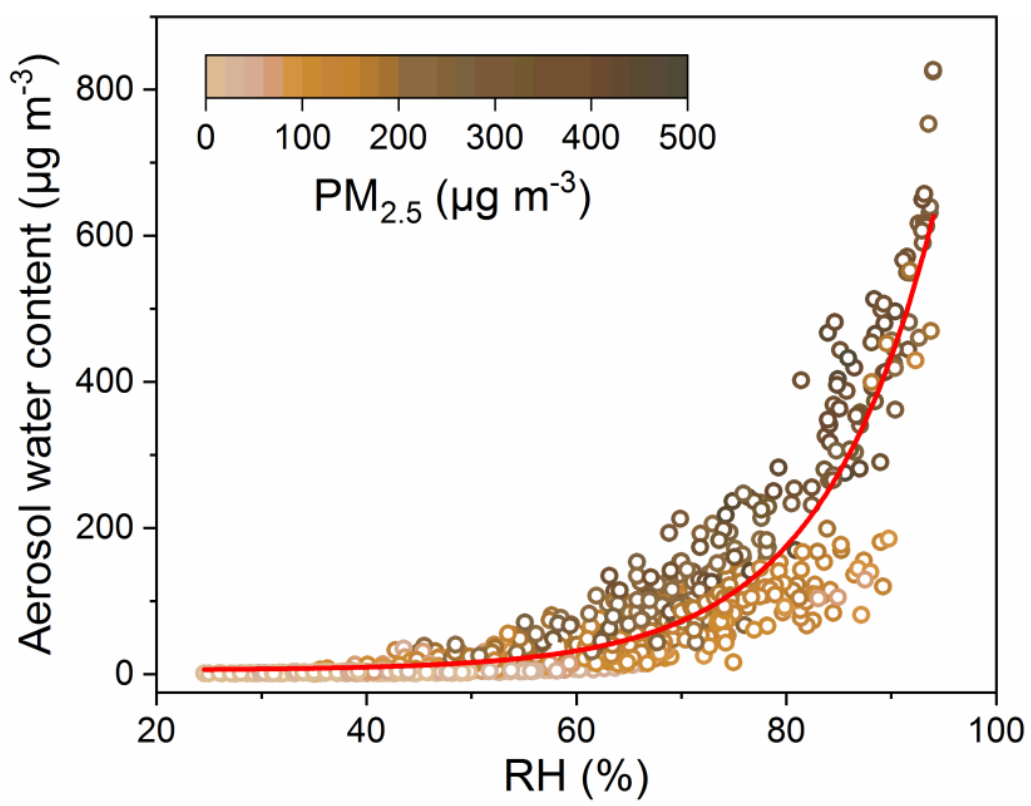

Figure S10. Relationship between RH and aerosol water content in Beijing in winter 2016. The markers represent aerosol water content and are colored by the $\mathrm{PM}_{2.5}$ concentrations. The red curve represents the exponential fitting between $\mathrm{RH}$ and aerosol water content, i.e., $y=5.5+0.1 e^{0.09 x}\left(R^{2}=0.85\right)$.

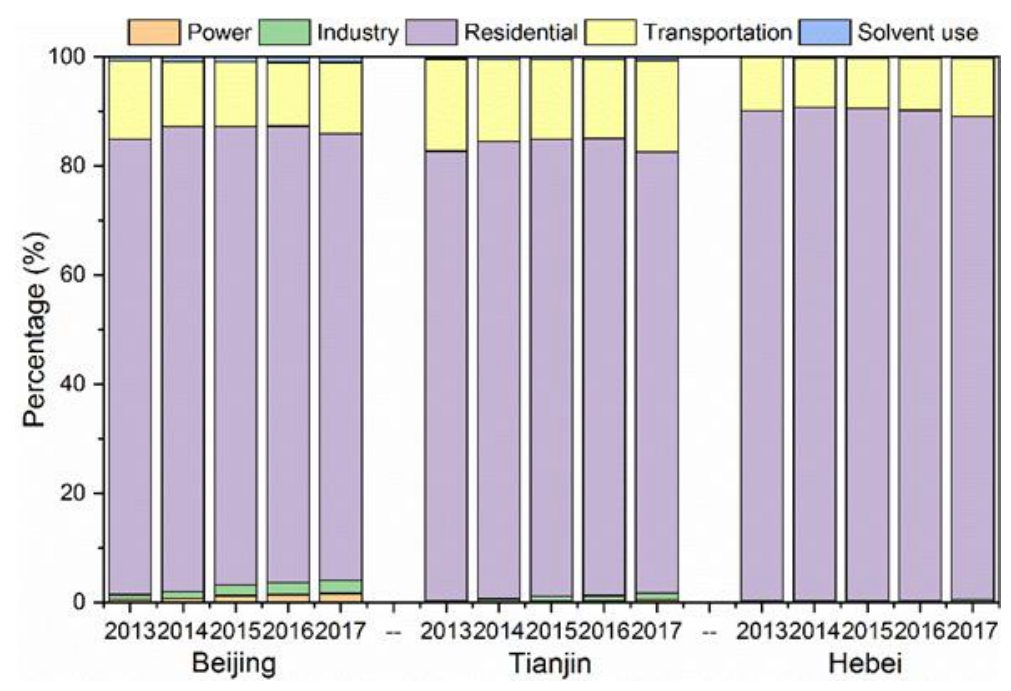

Figure S11. Emission percentages of HCHO across source sectors in winter (January, February, and December) from 2013 to 2017 in Beijing-Tianjin-Hebei.

\section{References}

Gelaro, R., McCarty, W., Suarez, M. J., Todling, R., Molod, A., Takacs, L., Randles, C. A., Darmenov, A., Bosilovich, M. G., Reichle, R., Wargan, K., Coy, L., Cullather, R., Draper, C., Akella, S., Buchard, V., Conaty, A., da Silva, A. M., Gu, W., Kim, G. K., Koster, R., Lucchesi, R., Merkova, D., Nielsen, J. E., Partyka, G., Pawson, S., Putman, 
W., Rienecker, M., Schubert, S. D., Sienkiewicz, M., and Zhao, B.: The Modern-Era Retrospective Analysis for Research and Applications, Version 2 (MERRA-2), J. Clim., 30, 5419-5454, https://doi.org/10.1175/jcli-d-16-0758.1, 2017.

Rao, Z. H., Chen, Z. M., Liang, H., Huang, L. B., and Huang, D.: Carbonyl compounds over urban Beijing: Concentrations on haze and non-haze days and effects on radical chemistry, Atmos. Environ., 124, 207-216, https://doi.org/10.1016/j.atmosenv.2015.06.050, 2016.

Sheng, J., Zhao, D., Ding, D., Li, X., Huang, M., Gao, Y., Quan, J., and Zhang, Q.: Characterizing the level, photochemical reactivity, emission, and source contribution of the volatile organic compounds based on PTR-TOF-MS during winter haze period in Beijing, China, Atmos. Res., 212, 54-63, https://doi.org/10.1016/j.atmosres.2018.05.005, 2018.

Song, S., Gao, M., Xu, W., Sun, Y., Worsnop, D. R., Jayne, J. T., Zhang, Y., Zhu, L., Li, M., Zhou, Z., Cheng, C., Lv, Y., Wang, Y., Peng, W., Xu, X., Lin, N., Wang, Y., Wang, S., Munger, J. W., Jacob, D. J., and McElroy, M. B.: Possible heterogeneous chemistry of hydroxymethanesulfonate (HMS) in northern China winter haze, Atmos. Chem. Phys., 19, 1357-1371, https://doi.org/10.5194/acp-19-1357-2019, 2019. 